\title{
Motivation
}

\section{The Role of Motivation and Academic}

Wellbeing - The Transition from

Secondary to Further Education in

STEM in Finland

\author{
KATARIINA SALMELA - ARO \\ Educational Sciences, University of Helsinki 10014, Finland. Email: Katariina. \\ salmela-aro@helsinki.fi
}

The transition from secondary education to tertiary education is challenging in Finland. Some of the key challenges are related to the competition rates in upper secondary education, gap years, low motivation towards STEM fields and a highly selective admission system to tertiary education; many opt out of STEM fields. In the current article, I approach these challenges in the context of expectancy-value-cost theory taking both a variable and person-oriented approach. Taking a variable-oriented approach we have identified that students' interest in STEM subjects decreases during secondary education. Taking a person-oriented approach, we can identify three different subgroups. The person-oriented approach reveals that $50 \%$ of the students show a decreasing interest in all subjects during secondary education. Additionally, we can identify two gendered pathways. One trajectory is more typical among males; for this group the interest in mathematics increases during secondary education. The other trajectory is more typical for females; with them, interest in mathematics decreases during secondary education while at the same time their interest in languages increases. When these groups are followed later on we can identify that those in the group in which interest in mathematics increases are more likely to pursue studies and to find employment in STEM fields compared with those in the group in which interest towards languages increased. In addition, we could identify four gendered motivational orientations towards work and education after the transition from secondary education: those interested in income (more males), those looking for future prospects, those combining work and family (more females), and those interested in society (more females). Recently, we have developed an intervention programme to promote interest and pathways towards STEM, which I will present as a way to bridge the transition from secondary to further education in STEM. 
According to a recent OECD (2019), report some of the key challenges in Finnish education are related to the completion rates in upper secondary education, gap years, low motivation towards the science, technology, engineering and mathematics (STEM) fields, the highly selective admission system to the tertiary education, and too many students opting out of STEM fields. Many talented and capable students are opting out of the STEM pipeline, and women remain overall underrepresented in STEM fields in Finland. These two issues represent an international phenomenon that has sparked considerable concern from policy makers and STEM professionals.

The OECD (2019) assessment report advises Finland to ease the transition from upper secondary school to higher education by making changes to its tertiary admissions practices that would offer more young people the opportunity to study. The recommendations are designed to reduce the number of people under the age of 30 who are currently without a study place or work in Finland. Finland has Europe's toughest university admission rates. One way the OECD recommends that Finland could make it easier to continue with higher studies is to reform the entrance criteria for university admission, which the group points out are currently among Europe's most highly selective. Assessors point out that low acceptance rates delay the start of higher education for many young people and force many applicants to take one or more involuntary gap years. Only a quarter of graduates of secondary education in Finland are able to continue their studies at an institute of higher education straight after finishing upper secondary school.

Among all participating OECD countries, Finnish students' science academic performance ranked number one in 2003, 2006 and 2009. In 2012, 2015 and 2018 their scores began to decrease. This decline put Finland on notice about its country's science programmes, as well as rather recent findings indicating that the percentage of Finnish students who expected to work in science occupations at the age of 30 was the lowest in all OECD countries. This waning interest in science, coupled with low science career aspirations (especially among females), worries Finns due to the potential negative impact it may have on the supply of the Finnish science labour force, support for scientific literacy, and Finnish society's overall wellbeing.

Another challenge during secondary education and the transition to tertiary education is students' stress and, related to this, their low wellbeing (SalmelaAro 2017). Quite recently, based on the rationale that school is a place where students work (Salmela-Aro and Tynkkynen 2012), the concept of burnout has been extended to schools and larger education contexts (Salmela-Aro 2017; Walburg 2014). School burnout as a new research topic has quickly gained international attention, which speaks to its perceived relevance across several nations (e.g. Herrman et al. 2019; May et al. 2015; Meylan et al. 2015; Yang and Chen 2016). Taken together, the phenomenon of school burnout can be observed among students from different educational systems and academic policies, thus indicating that it is a neither culturally nor geographically restricted concept (Walburg 2014). School burnout can be defined as a school-related syndrome, including three emotional, cognitive and behavioural components: exhaustion, a negative and cynical attitude towards school, and feelings of inadequacy as a student 
(Salmela-Aro 2017; Salmela-Aro et al. 2009). School engagement, in turn, can be defined as characterized by vigour, dedication to and absorption in school (Salmela-Aro 2017; Salmela-Aro and Upadyaya 2012). New results show that, in recent years, students' stress during secondary education has increased (School Health Study, 2019). A recent study has revealed that about a third of high school students suffer from school-related stress or even burnout (Salmela-Aro and Upadyaya in press).

High school transition is a critical stage for Finnish adolescents. In the Finnish educational system, students transition from comprehensive school to high school in tenth grade (15 or 16 years old), which also happens to be their first main school transition. Upon transitioning to high school, Finnish adolescents choose to pursue an academic or vocational track. As this paper aims to review the results related to motivational development across academic domains and subsequent educational and occupational choices in STEM fields, I focus on the students in the academic track. The Finnish educational system implements course-by-course tracking within schools but not academic tracking between schools in high school. Students are relatively free to choose difficult levels or numbers of classes in many subjects, which triggers dimensional comparison processes and develops relative strengths of motivation. Moreover, as part of their preparation for university study, students on the academic track strive to be successful with more challenging schoolwork in high school, which is oriented more towards social comparison and competition among peers than was the case in comprehensive school (Salmela-Aro and Tynkkynen 2012). These key characteristics of the Finnish educational system emphasize the importance of tracking individual and gender differences in motivational development during high school transition; nevertheless, these have been rarely investigated hitherto.

\section{Motivation and Wellbeing}

In the current paper, the aim is to approach the challenges mentioned in the context of the expectancy-value-cost theory and school wellbeing model (Eccles 2015; Salmela-Aro 2017). According to expectancy-value theory (EVT), students' task values (STV), the extent to which students perceive their tasks as interesting (i.e. intrinsic value), important (i.e. attainment value), and useful for their future (i.e. utility value), and the extent to which tasks strain students' psychological resources (i.e. cost) and related expectations, play an important part in academic learning, choices and attainments (Wigfield and Eccles 2000). High task values and success expectancies promote students' investment in their studies (e.g. effort, persistence and engagement; Eccles and Wigfield 2002), are associated with high achievement within specific domains (Bong 2001; Hulleman et al. 2008) and influence their future course selections in different subjects, such as studies in science (Bong 2001; Eccles 1994). 
Modern EVT of motivation posits that individuals' achievement, choices of and persistence in given tasks are influenced by two components: students' expectancies of successfully completing these tasks and the subjective value that they attribute to these tasks (Wigfield and Eccles 2019). The value aspect of motivation is influenced by students' intrinsic interest or importance or attainment, and utility value or usefulness of the task, and psychological cost (Eccles and Wigfield 2002). Ratings of interest in a task or domain (e.g. intrinsic value) are most closely linked to the inherent, immediate enjoyment one gets from engaging in an activity (Eccles and Wigfield 2002). When students place high intrinsic value on an activity they often become deeply engaged in it and can persist at it for a long time, particularly if they experience flow (Csikszentmihalyi 1997). Importance to oneself (e.g. attainment value) is most closely linked to the extent to which engaging in the task enacts central aspects of one's identities and core values; utility value is most closely linked to the relevance of the task to facilitating one's short- or long- term goals (Eccles and Wigfield 2002). In certain respects, utility value is related to the idea of extrinsic motivation, because when the STV of a task is primarily linked to its utility value, the activity is a means to an end rather than an end in itself (see Ryan and Deci 2016).

However, the activity also can reflect important goals that the person has come to hold very deeply, such as attaining a certain occupation. In this sense, utility value also connects to personal goals and sense of self, and so has some ties to attainment value. Attainment value is the relative personal/identity-based importance attached by individuals to engaging in various tasks or activities. According to Eccles, the relative within-person attainment value derives from the assumed fit of perceived task characteristics with the individual's core self schema, social and personal identities, and sought selves; that is, the extent to which tasks do or do not allow persons to manifest those behaviours that they view as central to their own core sense of themselves, or allow them to express or confirm important aspects of their central selves. For example, individuals whose identities are closely tied to being seen as an athlete will place much higher attainment value on doing sports than reading a book or serving on the debate team; in contrast, a person who identifies as being an intellectual rather than an athlete will place negative attainment value on doing sports. Similarly, a person who has a very central and strong traditional gender role identity will place much higher attainment value on tasks they believe to be consistent with their gender role identity than other tasks or activities; in fact they will likely attach quite negative attainment value to tasks that they think are contrary to their gender-role identity. The same would hold true for tasks or activities perceived to be core to many other social identities.

Cost, in turn, describes how engagement in an activity limits access to other activities, or strains one's psychological and physiological resources (Wigfield \& Eccles 2000). Even though cost has been included as a part of students' task values, its role in student motivation has been studied least (Wigfield \& Cambria 2010). However, the expectancy-value-cost model (Barron \& Hulleman 2015) suggests that the cost should be examined as a separate component of students' task-values, and 
that the role of cost in students' learning should be tested conjointly with their task values. Cost in learning situations can be viewed as the emotional or psychological costs students face while engaging in different academic tasks (Wigfield \& Eccles 2019). High psychological cost can increase withdrawal and giving up, but high cost can also provide students with opportunities to improve their abilities beyond what they have previously mastered and guide students' behaviour towards mastery of new learning goals (Schneider et al. 2020). Until recently cost, like attainment value, has been operationalized less fully and thus studied less comprehensively than intrinsic and utility value, in part because both cost and attainment value are complex multidimensional constructs. Research on cost has burgeoned in the last several years, and researchers have both proposed new dimensions of cost and developed new measures of addressing it (see Barron and Hulleman 2015). Researchers have shown that cost items factor separately from items measuring intrinsic, attainment, and utility values, and also separately predict outcomes, leading Barron and Hulleman to propose that EVT models be labelled Expectancy-Value-Cost Models.

Researchers have examined the extent to which students' expectancies and values interact to influence their achievement and have shown that these interactions add small but reliable increments in predictive validity (e.g. Nagengast et al. 2011; Trautwein et al. 2012). Findings show both that meaningful patterns in individuals' expectancies and values can be identified and that these patterns relate to achievement choices (e. g. Conley 2012). A point often discussed by Eccles (e.g. Eccles 2005) is that students' subjective-task-values for different activities do not operate in isolation or independently of each other. Rather, the differentiation of individuals' domain-specific subjective valuing of various tasks and activities will lead to hierarchies of subjective task-values. Eccles has argued that at the individual level, it is the relative placement of various tasks in an individual's hierarchy of subjective task-values that are the important predictors of their task and activity choices, rather than the valuing and success expectations of the activity itself. That is, people prefer tasks that are relatively higher in their own hierarchy over tasks lower in their hierarchy. These hierarchies likely are formed by factors ranging from individuals' experiences with different tasks, their success or failure with them, messages from parents and teachers about what are important things to do, and the appropriateness of doing different tasks depending on individuals' biological and social group memberships (see Eccles 1998).

Work focused more on understanding within-individual differences over time is showing the importance of such within-individual hierarchies of SVT across domains in predicting activity choices. Students who value mathematics more than languages are more likely to take advanced mathematics courses and a science college major than people who value both mathematics and language equally even though both groups value mathematics equally highly and do equally well in maths. 


\section{The Study}

We used an expectancy-value theoretical framework (Eccles 2009) to investigate subjective task values (STVs) attached to various subject domains. First, we examined the cost value of different subjects operationalized as exhaustion towards different subjects from comprehensive school to secondary education. Second, we examined the average joint trajectories of STVs in three domains (Finnish, mathematics/science, and social subjects) for students during the transition from comprehensive education to upper secondary education during the grades 9 to 11 from a variable-oriented approach (Guo et al. 2018). We used a personoriented approach in which we identified multiple trajectory groups with distinct joint developmental patterns of STVs across domains, and link these trajectory patterns to STEM aspirations four years beyond secondary school, and STEM participation six years beyond secondary school. Then, we explored possible gendered motivational trajectories and how they might contribute to possible gender differences in STEM fields. The divergent predictive patterns between variable- and person-oriented approaches are discussed. Third, we focus on the students' wellbeing and stress during their educational pathways and how it is related to their educational aspirations.

The relative STVs of a variety of subject domains are assumed to influence choice behaviours more so than course grades (Eccles 2009). Indeed, the process of career selection is inherently comparative: All options are assumed to be associated with costs, as one choice often eliminates other options (Eccles 2009). Let us think about the decision to major in mathematics at university. Students are likely to select this major only if they place high value on majoring in mathematics by comparing the mathematics major to other majors. Thus, students' relative STVs channel their educational and occupational decision-making and attainment.

A second possible explanation for declining motivational trajectories is to attribute it to a mismatch between an adolescent's developmental psychological needs and the school environment (Eccles et al. 1993a,b; Salmela-Aro 2017). Students expect to have more autonomy and independence in learning during adolescence; however, opportunities to serve adolescents' needs in a school environment are limited because of the isolative structure of many high schools and the demands on teachers to manage large student loads, often resulting in the use of controlling classroom strategies and normative grading. This mismatch contributes to a declining motivational trend and increasing stress with many students.

A developmental psychological perspective may help explain why heterogeneous trajectories emerge and offer theoretical rationales for why it is critical to track joint motivational trajectories across domains during high school transition. From developmental science, we know that educational and occupational aspirations begin to crystallize during the high school years (Eccles et al. 1993a,b). Having clear career goals would lead students to place higher value on subject domains closely related to those career plans than on others. For example, having a mathematics-related career plan was found to significantly promote one's perceived mathematics utility 
(Lauermann et al. 2017). However, based on our findings, Finnish students have been found to struggle with educational and occupational identity and only $20 \%$ of high school students have been shown to achieve educational and occupational identity (Mannerström et al. 2018).

Previous expectancy-value theory research has demonstrated that males are likely to perceive mathematics and science as more important, useful, and enjoyable than females, whereas females are likely to have higher STVs than males for language and social subjects throughout comprehensive and secondary school (Watt 2004; Wigfield et al. 2016). These studies have also documented that the gender gaps in mathematics STVs appear to be relatively stable or even slightly smaller during high school. Importantly, these gender differences have been found to be useful when explaining women's under-representation in STEM fields (Wang and Degol 2016). For example, Chow et al. (2012) found that eleventh-grade males were more likely than females to fall into a group that valued mathematics and science more than other subject areas, hence partially explaining gender disparities in the desire for STEM careers. By capturing gendered joint trajectories of STVs across multiple domains and examining their contributions to gender differences in STEM participation during post-high school transition, we can achieve a deeper understanding of how motivational-developmental processes characterizing different groups of students shape gendered pathways to STEM careers.

\section{Exhaustion with Respect to Different Subjects}

The dataset used to examine the emotional cost of different subjects was the Mind-the-Gap dataset, in which 2018 young people were followed from sixth grade onwards to high school. Using the Likert scale from 1 (not at all) to 7 (very much), they were asked to evaluate the emotional cost in terms of exhaustion towards six subjects: Finnish, foreign languages, mathematics, biology, physics and arts. The results showed that subject-related cost (exhaustion) changes during the transition from comprehensive education to secondary education (see Figure 1). Cost in terms of emotional exhaustion related to mathematics was highest among the task-values. Second highest cost in terms of emotional exhaustion was towards physics. After the transition to secondary education, mathematics-related exhaustion increased rapidly (Figure 1). This is an important result now that, according to the Finnish new educational reform, the importance of mathematics in secondary education becomes more important in terms of entrance to tertiary education. Thus the stress and exhaustion among students might even increase.

\section{Gendered Pathways towards STEM}

The dataset used to examine the second question about the developmental STVs was part of the Finnish Educational Transition Studies (FinEdu), an ongoing longitudinal study tracking a cohort of ninth-grade students from all comprehensive schools in 


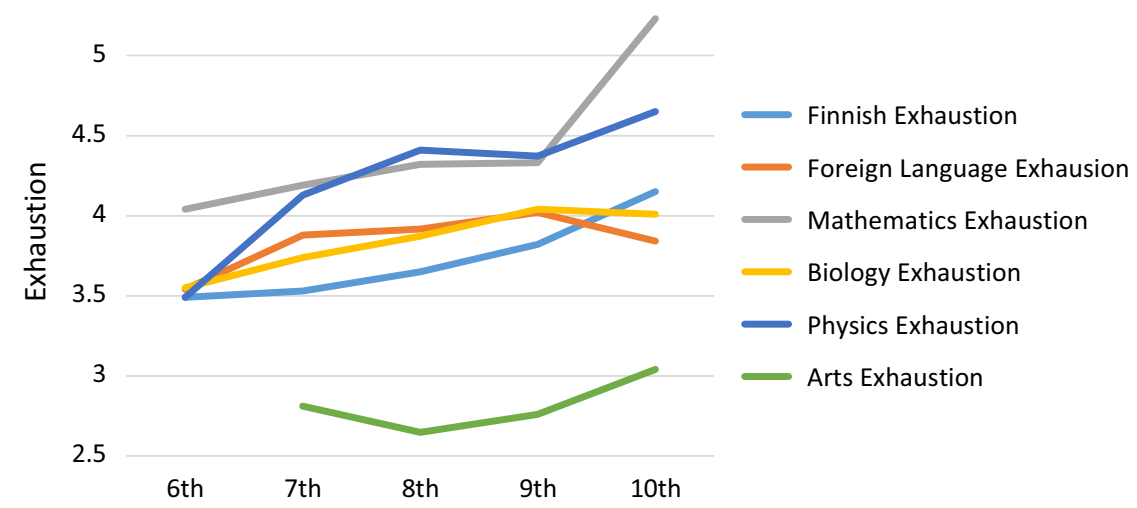

Figure 1. Emotional cost (exhaustion) related to different subjects from comprehensive school to high school. (To view this figure in colour please see the online version of this journal.)

a city in central Finland since 2004. We examined the developmental trajectories of students' STVs from ninth grade to eleventh grade. In total, 849 participants were included to test their motivational trajectories (from ninth grade to eleventh grade). We linked the students' motivational trajectories to post-high school variables four years post-high school $\left(M_{\mathrm{age}}=23.0\right.$ years $)$ and six years post-high school ( $M_{\text {age }}=25.4$ years). We integrated variable- and person-oriented approaches to examine how individual and gender differences in joint motivational trajectories across three subject domains influenced career development during high school transition. The results showed that students' STVs in different domains remained stable (in Finnish and social subject domains) or slightly declined (in mathematics and science domains) on average from comprehensive school to secondary education. However, when we took a person-oriented approach, we identified three differential trajectory patterns of STV change over time, suggesting how the trajectories in multiple domains shape each other. Additionally, between-person differences in STVs at ninth grade and within-person heterogeneous patterns (i.e. trajectory groups) of STVs were substantially associated with post-high school STEM aspirations and participation. Differential motivational developments of males and females across different subject domains play a vital role in contributing to gendered career choices and gender disparities in STEM fields.

Thus, taking a person-oriented approach, we could identify three different subgroups. The person-oriented approach reveals that among $50 \%$, interest in all subjects decreased during secondary education - this groups we called 'High but Decreasing All Subjects'. Next, we could identify two gendered pathways. One trajectory, 'Low but Increasing Mathematics and Science,' was more typical among boys; for this group their interest in mathematics increased during secondary education. The 'High and Increasing Finnish' trajectory was more typical for females; the interest in mathematics decreased during secondary education while their interest in languages increased. When these groups were followed later on we could identify 
that those in the group in which interest in mathematics increased were more likely to pursue studies and find employment in the STEM fields compared with those in the group in which the interest in languages increased.

Interestingly, we found two groups where students evidenced STV increases in Finnish or mathematics and science during the transition from comprehensive education to high school. These findings could be due to the autonomy of Finnish students to choose different levels of coursework. These two trajectory groups demonstrate how motivational developments in different domains influence each other through within-person dimensional comparison processes to evidence opposite patterns of development over time. Because of a perceived high dissimilarity between the verbal and mathematical domains (Guo et al. 2015), a motivation growth in Finnish leads to a relative decline in mathematics and science and vice versa (i.e. a contrasting effect). Motivational changes in social subjects are rather close to those in Finnish across different trajectory groups, given that both domains are likely to be perceived as similar (i.e. an assimilating effect).

The results showed that students in the Low but Increasing Mathematics and Science trajectory had lower mathematics and science STVs at grade 9 at the end of comprehensive school than those in the other two trajectory patterns. This finding raises the question of why students with lower STVs in mathematics and science at the onset of high school experienced STV increases throughout high school. The relative intra-individual hierarchy of STVs across domains and dimensional comparison processes can play a key role here. When compared with other domains, students in the Low but Increasing Mathematics and Science trajectory placed the highest value on mathematics and science at the end of comprehensive education. This relative priority pattern of STVs may have helped these students select coursework and devote more time and energy to the classes and activities that interested them and that fit closely with their personal goals (Guo et al. 2015, 2017; Wang and Eccles 2013). Consequently, these students may come to place more academic STVs on mathematics and science than on other subjects (Wigfield et al. 2016). In contrast, students in the High and Increasing Finnish group placed even higher value on Finnish than on mathematics and science at grade 9 in the comprehensive school. This might have directed them away from mathematics and science classes and activities, subsequently decreasing their perceived value of this domain. The third trajectory group was the High but Decreasing All Subjects group where the three domains were rated relatively similar.

Gender differences in STVs were identified for all subject domains at grade 9: boys placed more value on mathematics and science, whereas girls had higher STVs for Finnish and social subjects. This finding suggests that gender differences in STVs appear to emerge in early school years. While Jacobs et al. (2002; also see Watt 2004) reported that gender differences in mathematics STVs remain stable during high school transition, we observed a clear gender divergence in mathematics and science STVs, stemming from a greater decline in females' STVs. The gender gap in mathematics and science motivation is associated with an intensification of gendered socialization pressures by parents, peers and schools. 
Gender differences in both between- and within-person mechanisms in relation to different STVs significantly explained gender disparities in STEM aspirations and participation. The results address that gender differences in how individuals prioritize and develop STVs across domains may play a more prominent role in directing students to STEM educational and occupational pathways as compared with those in absolute levels of STVs. Females are more likely to place relatively low STVs on mathematics and science, experience a downward trend in mathematics and science, and experience an upward trend in Finnish STVs than males. Males are more likely to experience reverse motivational trajectories, even though some may have even lower STVs in mathematics and science compared with females at grade 9. These gendered motivational trajectories provide the foundation for gendered educational and career development and contribute to gender differences in preparedness for and long-term attainment in STEM fields.

In the Finnish educational system, the transition from secondary education to university is challenging and it takes a long time compared with many other countries. We linked the motivational trajectories to individual's STEM participation six years after post-high school transition. However, many participants were still studying in university at that time point, which did not allow us to assess their ultimate career fields. However, the delayed exposure to higher education, due to the highly competitive university system, makes a strong case for testing the effect of motivational trajectories on educational and career choices. During the post-high school transition, students may have difficulty keeping up their STEM career aspirations because most STEM majors required higher marks in matriculation and students often need to apply multiple times for University STEM programmes, which may lead them to re-initiate their career exploration processes. The strong predictive effect of motivational trajectory profiles suggests that the relative STVs in high school are highly influential in long-term career-related behaviour choices. The special features of the Finnish educational system warrant future research to investigate whether the findings can be replicated in other and different systems. In addition, we could identify four gendered motivational orientations towards work and education after the transition from secondary education: those interested in money (more males), those in prospects, those combining work and family (more females) and those interested in society (more females). These profiles also predicted gendered transition to STEM fields.

\section{Academic Wellbeing during Secondary Education}

Our recent results have shown that school-related stress increases during upper secondary education (Salmela-Aro and Upadyaya in press). The increased stress has been found to be related to the likelihood of having to take some involuntary gap years and a decrease of educational aspirations. It is worrying that a culture of performance may be prevalent in upper secondary education, where students feel they have to perform despite needing help. Our recent study asked upper secondary 
high school students to rate how strongly they agreed with statements such as 'when I wake up in the morning, I feel happy about going to school'. Only some $20 \%$ agreed while nearly half disagreed. All signs in the high school barometer point to a growing trend of student exhaustion; about $40 \%$ of respondents said they find studying to be psychologically stressful. One in five high school students said they need more help with schoolwork than they currently receive. Recent policy implications are now stressing the support offered to high school students and changes to the transition process to university. According to the new policy decisions, the entrance examinations will be revisited. However, the importance of grades in high school, in particular mathematics, will be greater than before. There is a risk that this leads to even increasing stress in upper secondary education and it can further increase the gendered processes in the Finnish educational system.

Finland has one of the most selective higher education systems in the OECD, with $67 \%$ of applicants rejected every year (OECD 2019). This high selectivity delays the start of tertiary studies for many applicants, forcing them to take involuntary gap years and repeat the entrance test. Only $25-30 \%$ of the upper secondary applicants are able to continue their tertiary studies immediately after graduation and the average age at which Finnish students are able to enter tertiary education first time is among the highest in OECD. Given the aim to get $50 \%$ of young people a tertiary degree by 2030 and the strong demand for high-skilled workers, the high selectivity and limited capacity of the higher education system is not appropriate.

As a new policy, one possible way to facilitate the continuum of engagement among adolescent students and young adults would be to develop innovative transition programs designed to help students achieve a deeper understanding of their study and career possibilities (Vinson et al. 2010) and to enhance their career exploration (Perry 2008). Such transition programmes could feature a wide range of novel, innovative, and traditional activities (e.g. small group tutoring, research projects, Google mapping) with an emphasis on clarifying future possibilities and the purpose of study courses and activities for students (for more examples, see Vinson et al. 2010). Moreover, helping students to identify their intrinsic career values prior to the transition to higher education/work may also enhance late adolescents' engagement in school/work (Sortheix et al. 2013). Teachers and educators could incorporate such programmes in their own teaching and thus support students' successful transition to higher education/work.

\section{References}

Barron KE and Hulleman CS (2015) Expectancy-value-cost model of motivation. Psychology 84, 261-271.

Bong M (2001) Between- and within-domain relations of academic motivation among middle and high school students: self-efficacy, task value, and achievement goals. Journal of Educational Psychology 93(1), 23.

Chow A, Eccles JS and Salmela-Aro K (2012) Task value profiles across subjects and aspirations to physical and IT-related sciences in the United States and Finland. Developmental Psychology 48(6), 1612-1628. 
Conley AM (2012) Patterns of motivation beliefs: combining achievement goal and expectancy-value perspectives. Journal of Educational Psychology 104(1), 32.

Csikszentmihalyi M (1997) Finding Flow: The Psychology of Engagement with Everyday Life. New York: Basic Books.

Eccles JS (1994) Understanding women's educational and occupational choices: applying the Eccles et al. model of achievement-related choices. Psychology of Women Quarterly 18(4), 585-609.

Eccles JS (1998) Perceived control and the development of academic motivation. Monographs of the Society in Child Development 63(2-3), 221-231.

Eccles JS (2005) Subjective task value and the Eccles et al. model of achievementrelated choices. Handbook of Competence and Motivation. New York: Guildford, pp. 105-121.

Eccles, JS (2009) Who am I and what am I going to do with my life? Personal and collective identities as motivators of action. Educational Psychologist 44, 78-89.

Eccles JS and Wigfield A (2002) Motivational beliefs, values, and goals. Annual Review of Psychology 53(1), 109-132.

Eccles JS, Midgley C, Wigfield A, Buchanan CM, Reuman D, Flanagan C and Iver DM (1993a) Development during adolescence. American Psychologist 48(2), 90-101.

Eccles JS, Wigfield A, Midgley C, Reuman D, Iver DM and Feldlaufer H (1993b) Negative effects of traditional middle schools on students' motivation. The Elementary School Journal 93(5), 553-574.

Guo J, Parker PD, Marsh HW and Morin AJ (2015). Achievement, motivation, and educational choices: a longitudinal study of expectancy and value using a multiplicative perspective. Developmental Psychology 51(8), 1163.

Guo J, Marsh HW, Parker PD, Morin AJ and Dicke T (2017) Extending expectancyvalue theory predictions of achievement and aspirations in science: dimensional comparison processes and expectancy-by-value interactions. Learning and Instruction 49, 81-91.

Guo, J, Wang, M, Ketonen, E, Eccles JS and Salmela-Aro K (2018) Joint trajectories of task value in multiple subject domains: from both variable- and patterncentered perspectives. Contemporary Educational Psychology 55, 139-154.

Herrmann J, Koeppen K and Kessels U (2019) Do girls take school too seriously? Investigating gender differences in school burnout from a self-worth perspective. Learning and Individual Differences 69, 150-161.

Hulleman CS, Durik AM, Schweigert SB and Harackiewicz JM (2008) Task values, achievement goals, and interest: an integrative analysis. Journal of Educational Psychology 100(2), 398.

Jacobs JE, Lanza S, Osgood DW, Eccles JS and Wigfield A (2002) Changes in children's self-competence and values: gender and domain differences across grades one through twelve. Child Development 73(2), 509-527

Lauermann F, Tsai Y-M and Eccles JS (2017) Math-related career aspirations and choices within Eccles et al.'s expectancy-value theory of achievement-related behaviors. Developmental Psychology 53(8), 1540-1559.

Mannerström R, Hietajarvi L, Muotka J and Salmela-Aro K (2018) Identity profiles and digital engagement among Finnish high school students. Cyberpsychology: Journal of Psychosocial Research on Cyberspace, 12(1), 2. https://doi.org/10. 5817/CP2018-1-2

May RW, Bauer KN and Fincham FD (2015) School burnout: diminished academic and cognitive performance. Learning and Individual Differences 42, 126-131. 
Meylan N, Doudin P A, Curchod-Ruedi D and Stephan P (2015) Burnout scolaire et soutien social: l'importance du soutien des parents et des enseignants. Psychologie Française 60(1), 1-15.

Nagengast B, Marsh HW, Scalas LF, Xu MK, Hau KT and Trautwein U (2011) Who took the ' $x$ ' out of expectancy-value theory? A psychological mystery, a substantive-methodological synergy, and a cross-national generalization. Psychological Science 22(8), 1058-1066.

OECD (2019) Investing in Youth in Finland. Paris: OECD.

Perry C (2008) School engagement among urban youth of color. Criterion pattern effects of vocational exploration and racial identity. Journal of Career Development 34, 397-422.

Ryan, RM and Deci EL (2016) Facilitating and hindering motivation, learning, and well-being in schools: research and observations from self-determination theory. Handbook of Motivation at School. London: Taylor \& Francis, p. 96.

Salmela-Aro K (2017) Dark and bright sides of thriving - school burnout and engagement in the Finnish context. European Journal of Developmental Psychology 14(3), 337-349. https://doi.org/10.1080/17405629.2016.120751

Salmela-Aro K, Kiuru N, Leskinen E and Nurmi JE (2009) School burnout inventory: reliability and validity. European Journal of Psychological Assessment 25(1), 48-57. https://doi.org/10.1027/1015-5759.25.1.48

Salmela-Aro K and Tynkkynen L (2012) Gendered pathways in school burnout among adolescents. Journal of Adolescents 35, 929-939.

Salmela-Aro K and Upadyaya K (2012) Schoolwork engagement inventory. European Journal of Psychological Assessment 28(1), 60-67. https://doi.org/10. 1027/1015-5759/a000091

Salmela-Aro K and Upadyaya K (in press) School engagement and burnout profiles during high school - the role of socio-emotional skills. European Journal of Developmental Psychology.

Schneider B, Krajcik J, Salmela-Aro K and Lavonen J (2020) Learning Science. The Value of Crafting Engagement in Science Environments. New Haven: Yale University Press.

School Health Study (2019) Finnish School Health Promotion Study. Finnish Institute for Health and Welfare.

Sortheix FM, Dietrich J, Chow A and Salmela-Aro K (2013) The role of career values for work engagement during the transition to working life. Journal of Vocational Behavior 83(3), 466-475.

Trautwein U, Marsh HW, Nagengast B, Lüdtke O, Nagy G and Jonkmann K (2012) Probing for the multiplicative term in modern expectancy-value theory: a latent interaction modeling study. Journal of Educational Psychology 104(3), 763.

Vinson D, Nixon S, Walsh B, Walker C, Mitchell E and Zaitseva E (2010) Investigating the relationship between student engagement and transition. Active Learning in Higher Education 11(2), 131-143.

Walburg V (2014) Burnout among high school students: A literature review. Children and Youth Services Review 42, 28-33.

Wang M-T and Degol JL (2013) Motivational pathways to STEM career choices: using expectancy-value perspective to understand individual and gender differences in STEM fields. Developmental Review 33(4), 304-340.

Wang M-T and Degol JL (2016) Gender gap in Science, Technology, Engineering, and Mathematics (STEM): current knowledge, implications for practice, policy, and future directions. Educational Psychology Review 29(1), 119-140 
Wang M-T and Eccles JS (2013) School context, achievement motivation, and academic engagement: a longitudinal study of school engagement using a multidimensional perspective. Learning and Instruction 28, 12-23.

Watt HMG (2004) Development of adolescents' self-perceptions, values, and task perceptions according to gender and domain in 7 th- through 11th-grade Australian students. Child Development 75(5), 1556-1574.

Wigfield A and Cambria J (2010) Achievement motivation. The Corsini Encyclopedia of Psychology and Behavioral Science. New York: Wiley, pp. 1-2.

Wigfield A and Eccles JS (2000) Expectancy-value theory of achievement motivation. Contemporary Educational Psychology 25(1), 68-81.

Wigfield A and Eccles JS (2019) 35 Years of Research on Students' Subjective Task Values and Motivation: A Look Back and a Look Forward. Amsterdam: Elsevier.

Wigfield A, Tonks S and Klauda SL (2016) Expectancy-value theory. In KR Wentzel and DB Miele (eds), Handbook of Motivation at School. New York: Routledge, pp. $55-74$.

Yang $\mathbf{H}$ and Chen $\mathbf{J}$ (2016) Learning perfectionism and learning burnout in a primary school student sample: a test of a learning-stress mediation model. Journal of Child and Family Studies 25(1), 345-353.

\section{About the Author}

Katariina Salmela-Aro is Professor of Educational Sciences and Psychology, University of Helsinki, Finland, Marie Curie Visiting professor ETH Zurich, and Visiting Professor Institute of Education University College London. She is the Past-President of the European Association for Developmental Psychology, and Member of Finnish Science and Letters. She is director of several ongoing longitudinal studies among young people: FinEdu, LEAD, Mind-the-Gap. Her key research themes are educational transitions, school engagement and burnout, optimal learning, life-span models of motivation and related interventions and policy implications. She has published over 250 papers and chapters and received several national/international large-scale grants from the Academy of Finland and the National Science Foundation. She is a member of EU-granted EuroCohort aiming to develop a European-wide longitudinal survey of child and youth wellbeing. 